\title{
XLV. A method of finding the refractive index of a liquid; applicable when the liquid is not homogeneous
}

\section{T. H. Littlewood M.A.}

To cite this article: T. H. Littlewood M.A. (1894) XLV. A method of finding the refractive index of a liquid; applicable when the liquid is not homogeneous, Philosophical Magazine Series 5 , 37:228, 467-470, DOI: 10.1080/14786449408620574

To link to this article: http://dx.doi.org/10.1080/14786449408620574

曲 Published online: 08 May 2009.

Submit your article to this journal $\pi$

ЏلI Article views: 2

Q View related articles $\longleftarrow$ 
Method of finding the Refractire Index of a Liquid. 467 already pointed out that the darkness inside a drawer just pulled out, if the operator is sitting at a table in front of a window with a good light, is such that fine fibres can readily be seen upon it as a background. No velvet or smoked surface or artificial blackness of any lind is comparable with it. On such backgrounds fine fibres are to all intents and purposes invisible. What is in many respects preferable to the dark background, at least in certain operations, is a plain lookingglass lying on the table. Fibres resting upon it become intensely brilliunt and visible, provided the eye is so placed as not to see the sky light itself reflected from the mirror. One method of making the fibres very easily visible without influencing their torsion, is to smoke them with burning magnesium or arsenic. I do not suggest arsenic, but I mention it because of the very beautiful effect I once observed, after destroying all life in a small hot-house by burning a large quantity of bengal fire in which orpiment is a considerable constituent. All the spider-webs remained perfect with the spiders in their places as though alive, and the webs were of a dazzling white but perfect in form, undragged by the weight of the white arsenic upon them, thus contrasting strongly with the catenary distorted webs so much admired in frosty weather. It was this observation that suggested the magnesium smoking.

These last few points hardly come directly under the title of this paper, but I thought them worth adding as bearing upon the successful design of apparatus in which the full limit of delicacy and accuracy obtainable by the quartz fibre may be obtained, and upon the practical details of its treatment.

XLV. A Method of finding the Refractive Index of a Liquid; applicalle when the Liquid is not Homogeneous. By T. H. LITTLEWOOD, M.A.*

Apparatus required.

THE chief piece of apparatus required for the method is a 1 telescope with fixed wires in the eyepiece, arranged so as to be capable of motion along a horizontal scale, without changing its inclination to the vertical. The horizontal motion can be measured either by a vernier or by a micrometer-screw.

* Communicated by the Physical Society : read February 23, 1804. 
The liquid whose refractive index is to be determined is placed in a glass vessel about 3 feet away from the telescope, and with its level slightly below that of the telescope.

A scale of glass (or some material not acted on by the liquid) is placed vertically in the liquid and illuminated by monochromatic light. The position of the telescope on the horizontal scale is then taken when observing the various divisions on the vertical scale. From these readings the index of refraction can be ascertained.

First case.-When the liquid is homogeneous (fig. 1).

Fig. 1.

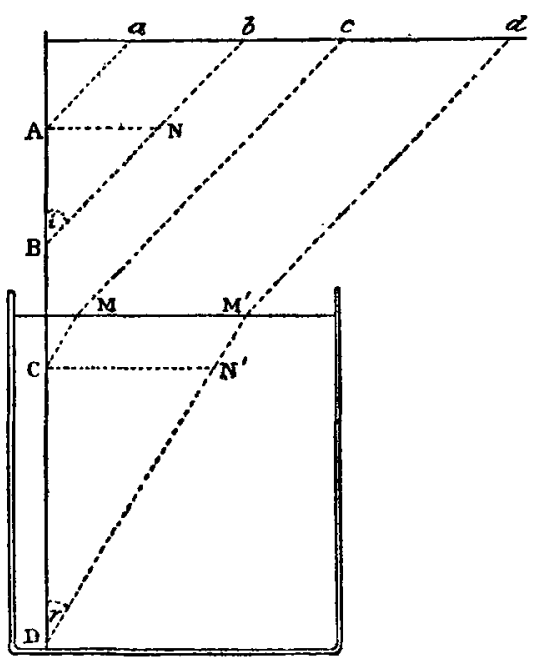

Suppose A, B are two points on the vertical scale ont of the liquid ; C, D two points within the liquid. Suppose $a, b, c, d$ are the positions of the telescope on the horizontal scale when observing these points. Then $\mathrm{A} a, \mathrm{~B} b$ are parallel; and if $\mathrm{CM} c, \mathrm{DM}^{\prime} d$ are the directions of the axis of the pencil of light from $\mathrm{C}$ and $\mathrm{D}, \mathrm{M} c, \mathrm{M}^{\prime} d$ are parallel, and also $\mathrm{CM}$, $\mathrm{OM}^{\prime}$ are parallel. Draw $\mathrm{AN}$ and $\mathrm{CN}^{\prime}$ parallel to $a b c d$. $\mathrm{AN}=a b, \mathrm{CN}^{\prime}=c d$.

$$
\begin{aligned}
& \therefore \tan \mathrm{AB} b=\frac{a b}{\mathrm{AB}}, \text { and } \tan \mathrm{CDM}^{\prime}=\frac{c d}{\mathrm{CD}} . \\
& \therefore \mu=\frac{\sin i}{\sin r}=\frac{\sin \mathrm{AB} b}{\sin \mathrm{CDM}^{\prime}}=\frac{a b}{c d} \times \sqrt{\frac{c d^{2}+\mathrm{CD}^{2}}{a b^{2}+\mathrm{AB}^{2}} .}
\end{aligned}
$$


Second case.-When the liquid is not homogeneous (fig. 2).

Fig. 2.

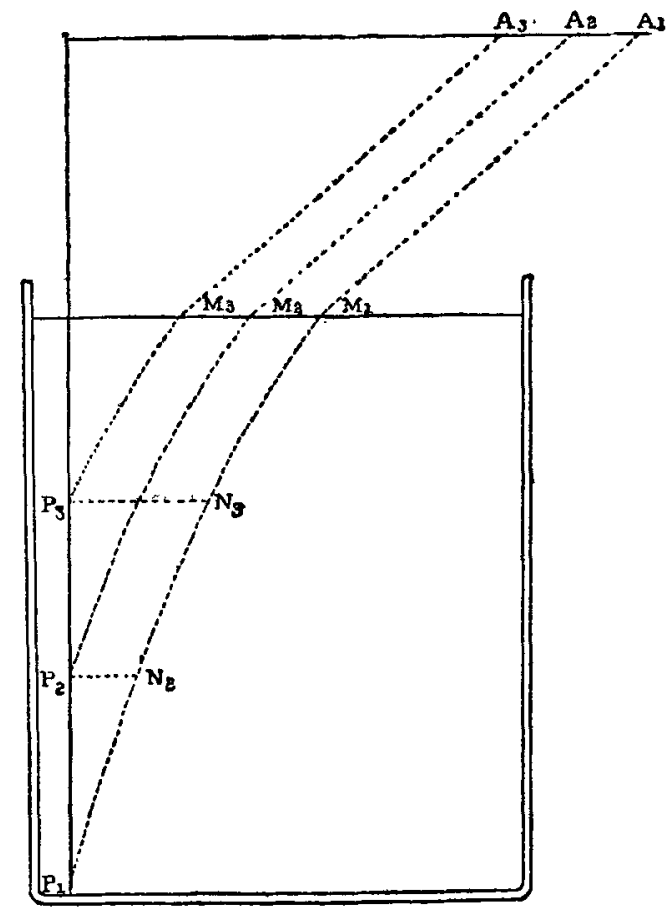

The liquid is supposed to have the same density at the same depth, which must be the case if it is at rest. The path of the axis of the pencil of light from any point on the scale which enters the telescope must be a curve.

Suppose $\mathrm{P}_{1}, \mathrm{P}_{2}, \mathrm{P}_{3}$ various points on the vertical scale, and $A_{1}, A_{2}, A_{3}$ the corresponding positions of the inclined telescope when observing them. Suppose $M_{1}, M_{2}, M_{3}$ are the points where the axis of the pencil cuts the surface of the liquid, and draw $\mathrm{P}_{2} \mathrm{~N}_{2}, \mathrm{P}_{3} \mathrm{~N}_{3}$ parallel to the surface. Then it is clear that, since $\mathrm{M}_{1} \mathrm{~A}_{1}, \mathrm{M}_{2} \mathrm{~A}_{2}, \mathrm{M}_{3} \mathrm{~A}_{3}$ are parallel, $\mathrm{P}_{2} \mathrm{M}_{2}$ is the same curve as $\mathrm{N}_{2} \mathrm{M}_{1}$ moved horizontally, parallel to itself, through the distance $\mathrm{P}_{2} \mathrm{~N}_{2}$ or $\mathrm{A}_{1} \mathrm{~A}_{2}$. $\mathrm{P}_{3} \mathrm{M}_{3}$ is the same curve as $N_{3} M_{1}$ moved through the distance $P_{3} N_{3}$ or $A_{1} A_{3}$. Similarly for other points.

Hence, by taking a number of points on the vertical scale and finding the corresponding positions of the telescope, and then plotting a curve having the vertical distances from the 
lowest point for ordinates, and the observed distances through which the telescope has been moved from its first position as abscissæ, we can construct the path of the axis of the pencil through the liquid.

A previous observation of different points on the scale, before the liquid is poured into the vessel, gives the inclination of the telescope to the vertical, as in the first case. By measuring the inclination to the vertical of the tangent to the curve obtained, we can determine the refractive index at the various points of the liquid.

Assuming the curve for a short distance to be a straight line, the index of refraction of the layer of liquid between any two points can be calculated as in the first case, and a similar formula will be true.

XLVI. Transformations of Mechanical into Chemical Energy. (Third Paper.) Action of Shearing-Stress (continued;. By M. Carey Lea.

THAT mechanical energy may be transformed into chemical 1 has been, I believe I may say, well proved by the reactions described in the previous papers of this series. But the matter is one of sufficient importance to make it desirable to accumulate evidence and to obtain a solid foundation of fact on which to rest the argument.

In the paper which described the effects of shearing-stress (Phil. Mag. Jan. 1894) I was able to cite one instance only in which the decomposition-product was obtained in easily weighable quantities. More lately others have been obtained, among them one, mercuric oxide, in which it can be determined how many units (gram-metres) of mechanical energy have been transformed into chemical.

Silver oxide precipitated and dried in the absence of daylight is soluble without residue in ammonia. After trituration, therefore, the unchanged portion is easily removed by that solvent.

1. Half a gram of silver oxide wholly soluble in ammonia was triturated for 20 minutes in a porcelain mortar, the unchanged portion was removed by ammonia, the residue was treated with nitric acid, filtered, and the silver thrown down by hydrochloric acid.

Silver chloride obtained. . . . 0402,

Corresponding to metallic silver . $\cdot 0303$.

The use of a porcelain mortar is attended with the dis- 